or in obstinate cases $50,000 \mathrm{~m} . \mathrm{u}$ bi-weekly, give very satisfactory results, and so far I have not failed to relieve one case. In cases where bleeding has not ceased entirely the injections should be given only in the first half of the intermenstruum - that is, on the first, fourth, eighth, eleventh, and fifteenth days following the cessation of bleeding, imitating the follicular phase of the ovary. Cases of therapeutic menopause, such as those following radium or bilateral oöphorectomy, need massive doses-that is, 50,000 m.u. - either every four or every two days; $1 \mathrm{~m} . \mathrm{u}$. (Schering) is equivalent to five international units, and these massive doses may be gradually reduced as symptoms are ameliorated, and often left ofi entirely, or maintained for a time, by administration of dragees alone. This treatment is somewhat expensive, but the patient is well rewarded by the certain relief of these distressing symptoms.

\section{Post-herpetic Pain}

Dr. W. Lofthouse (Jamaica) writes: In reply to Dr. H. Lewis-Philipps's (Whitland) request (December 22nd, 1934, p. 1185) for suggestions as to treatment for post-herpetic pains, I think if he will give a few doses of pituitrin (P. D. and Co.), 1 c.cm. at intervals of two days, he will find that it will give relief, and permanent relief. If used in the very early stage of the eruption one dose given daily for two days, then a dose given every other day for two more treatments, I think he will find that the eruption will dry up very much sooner, and that there will be no pains, which are so distressing.

\section{Income Tax}

Use of Private House

"I. C. H." is in partnership, and the firm has a central surgery. He lives in " a small house," rent $£ 70$, which has a garage built into it, and keeps one maid, who attends to the telephone and certain calls and professional visitors. What allowances can he claim? The authorities offer only $5 \mathrm{~s}$. a week in respect of the telephone.

** Five shillings a week seems quite inadequate, but "I. C. H." is not in a position to enforce a substantial claim. The fact that if it were not for the telephone he might not keep a maid does not assist; the only reliable basis of claim is the ratio between private and professional use of all services, etc.; for which inclusive payments are made. On that basis there should aptoarently be only a small ratio applied to the domestic scrvice cost to ascertain how much is chargeable professionally. Some allowance should certainly be made for the garage-the fact that it is "built-in" does not matter ; so is a tradesman's shop. " I. C. H." might press for $10 \mathrm{~s}$. a week for the maid, half the telephone cost (or the exact proportion if known), and $7 \mathrm{~s} .6 \mathrm{~d}$. a week in respect of the garage rent and rates.

\section{Liability of Assistant}

"M. E. K." held a post at $£ 300$ per annum from January 6 th to November 10th, 1934. From November 17th he took a second post at $£ 336$, but in the latter case he has to provide a car. The car cost £52, and the insurance costs $£ 12$ per annum. $\mathrm{He}$ is single and supports his mother. What is his liability?

** For 1933-4 (that is, the year to April 5th, 1934) he is apparently exempt. For 1934-5 he will be liable on 31/52 of $£ 300$ plus $20 / 52$ of $£ 336$-say, $£ 179+£ 130=£ 309$. From this he can deduct $20 / 52$ of the annual cost of running the car, including 20 per cent. depreciation and the expense of renewing instruments, etc. $\mathrm{He}$ should claim the "dependent relative allowance" in respect of his mother, which will free him from payment on $£ 25$ of his net income. The amount of tax payable should be about $£ 8$ for the year to April 5th, 1935.

\section{LETTERS, NOTES, ETC.}

\section{High Blood Urea}

Dr. Edward Collier (Felling-on-Tyne) writes: The very interesting report by Dr. D. E. Dunnill (Journal, January 26 th, p. 154) of a case with an abnormally high blood urea reminds me of a similar case which came under my care in October, 1931. The patient, a man aged 61 years, had led a vigorously busy life as the proprietor of a fish-and-chip restaurant until about Christmas, 1930, when he began to complain of loss of appetite and general malaise. Since then he had been becoming progressively weaker, and had lost about two stone in weight. He also complained of day-and-night frequency of micturition, though there was no dysuria or haematuria, and the stream of urine passed was in no way diminished. The chief abnormality found on examination was a simple enlargement of the prostate. Also, the cardiovascular system showed arteriosclerotic changes. The blood pressure was 200 systolic, 124 diastolic. The urine was pale. specific gravity 1020 , and a haze of albumin was present. The blood urea was no less than 370 mg. per cent. Despite this, operation was deemed to be his only chance. Under local anaesthesia a tube was put into the bladder. Drainage was quite satisfactory, and he appeared to be going on quite well when he died suddenly on November 9th, 1931. Professor Turner, who undertook the operation, informed me at the time that the blood urea figure was the highest he had ever known in a surgical case.

Chloroform Treatment for Tapeworm

Dr. P. W. Philip (Huntly) writes: A local chemist, who has worked in South Africa, is very enthusiastic over a form of treatment for tapeworm which a doctor friend used in that country. This consisted of administering chloroform in simple syrup by mouth to the patient. To a male patient; in whose appendix a live segment of $T$. saginata had been found at operation twelve days previously, a 20-minim dose of chloroform was administered at 6 a.m., 8 a.m., and 10 a.m., and $1 \mathrm{oz}$. of castor oil at 12 noon. Many segments and two to three feet of worm were evacuatcd, but no head was observed. Three days later, after another dose of castor oil, three 20-minim doses of chloroform were administered at two-hourly intervals, followed by $1 \frac{1}{2} \mathrm{oz}$. of castor oil. Several feet of tapeworm were passed that evening, including what appeared to be the head. The specimen was sent for examination, and the laboratory reported that the head was found. My partner, Dr. Garson, sen., gave one course of this treatment to a female patient who had suffered from tapeworm for years, and had been unsuccessfully treated with ext. filicis liq. on several occasions. This occurred three years ago. No head was found among the segments passed, but to her knowledge this patient has not passed a segment of tapeworm since that time, and has remained in perfect health. In my opinion, one course of treatment would be enough in a well-cleared bowel. There were no complications in these two cases, and we shall not hesitate to use tinis treatment in the future. My thanks are due to $\mathrm{Mr}$. George Davidson, chemist, Huntly, for suggesting this treatment, to Dr. Garson, sen., for allowing me to quote his case, and to Dr. Smith, the Laboratory, City Hospital, Aberdeen, for allowing me to use his reports.

\section{"Radium Therapy: Value and Limitations"}

Mr. F. D. OWEN-KING (managing director, General Radiological and Surgical Apparatus Co. Ltd.) writes: May I be permitted to point out an error in the account, under the above heading, of a meeting of the Medical Society of London, reported in the Journal of March 2nd (p. 440)? Mr. Jocelyn Swan is recorded as mentioning a new lowvoltage $x$-ray therapy machine working at 600 volts. $\mathrm{He}$ is, of course, referring to the so-called Chaoul " contacttherapy " apparatus, which operates at $60 \mathrm{kV}$-that is, 60,000 volts

** We learn from Mr. Jocelyn Swan that he did mention $600^{*}$ volts in error for $60 \mathrm{kV}$ at the meeting in question.

\section{Ocular Torticollis or Squint}

Mr. T. KeIth Lyle (London, W.1) writes to suggest that a mistake has occurred in the memorandum by Mr. E. Temple Smith of Sydney, on "Ocular Torticollis or Squint" (March 2nd, p. 416). The third word in the fifth line, "rectus," should, he thinks, be "oblique."

\section{Corrigendum}

The report of the proceedings of the Section of Medicine at the Royal Academy of Medicine in Ireland, supplied to us officially, contained an error (February 23rd, p. 382). Professor Henry Moore was recorded as saying in reference to bundle-branch block that he favoured the old nomenclature in preference to the new. In fact, what he said was the opposite.

\section{Vacancies}

Notifications of offices vacant in universities, medical colleges, and of vacant resident and other appointments at hospitals will be found at pages $48,49,50,51,52,53,54,55$, and 58 of our advertisement columns, and advertisements as to partnerships, assistantships, and locumtenencies at pages 56 and 57.

A short summary of vacant posts notified in the advertisement columns appears in the Supplement at page $\mathbf{9 2}$. 